\title{
DESCRIPCIÓN REFLEXIVA SOBRE LA CULTURA DEL CONSUMO EN CENTROS COMERCIALES EN EL VALLE DE TOLUCA, MÉXICO
}

\author{
Felipe GONZÁLEZ ORTIZ; Abraham OSORIO BALESTEROS; \\ Sergio VEGA BOLAÑOS \\ Universidad Autónoma del Estado de México \\ felsus1@yahoo.es, sub_abraham@yahoo.com.mx, sergio.vegab@yahoo.com.mx
}

\begin{abstract}
REFLECTIVE DESCRIPTION ON THE CULTURE OF CONSUMPTION IN SHOPPING CENTERS IN THE TOLUCA VALLEY, MEXICO
\end{abstract}

Resumen: A partir del estudio de un centro comercial de elite se brindan tres miradas en torno a la composición estética de la ciudad y el interior del mismo como expresión, a la vez, de un sentido colectivo de similaridad entre los consumidores y de distinción. De esta forma, se establece una articulación entre consumo y estilos de vida

Abstract: From the study of one Mall's, give us three observations around aesthetics composition of the city and the interior of Himself as an expression, at once, shared collective sense of similarity, between consumers, and distinction are provided. Of This way, a link between consumption and establishing lifestyle.

Palabras clave: Mercados De Elite, Centros Comerciales, Estética Del Espacio Markets Elite, Shopping Centers, Aesthetic Space 


\section{Introducción}

El siguiente artículo presenta una interpretación sobre la configuración de un tipo social de consumidor, que está en ciernes, ante la emergencia de un centro comercial en el Valle de Toluca, el cual representa, en su concepto y definición, a la cultura del consumo. Es decir, trata de dar cuenta de las aspiraciones y seducciones que este tipo de mercado busca crear entre los clientes, en un momento en que la cultura moderna parece empecinarse por resaltar una suerte de personalidad autentica derivada de un consumo específico de artículos.

Los antecedentes históricos del tema se encuentran en el Libro de los pasajes, escrito originalmente en 1927 por Walter Benjamin, en que el autor describe la conformación de lo social a partir del consumo moderno que el escaparate (la vitrina) propone. En dicho libro se percibe que en el escaparate se da una disposición de bienes de consumo para el disfrute y la obtención de una experiencia de goce y placer, en tanto busca informar sobre la marca, el prestigio y status que enaltece su consumo; y en cuanto destaca supuestas distinciones sociales que genera la compra de algún producto dispuesto en la vitrina.

Centramos la mirada en el centro comercial llamado Galerías Toluca, inaugurado el 7 de octubre de 2914 en el más suspicaz de los silencios ${ }^{1}$, y cuya apertura coincidió con el desarrollo de un proyecto de investigación sobre sociedad, cultura y mercados que desarrollamos en nuestro grupo de investigación, del cual formamos parte quienes escribimos este texto, y que nos llevó a conocer dicho centro en distintos momentos. Este centro comercial tiene una característica que lo vuelve singular con respecto a otros del mismo tipo que se encuentran en el Valle de Toluca: uno de sus establecimientos (denominado Liverpool) maneja un estilo gourmet alrededor del cual giran otros establecimientos de alimentos. Tan es así, que los dependientes de tales establecimientos en los primeros treinta días de su surgimiento se dedicaron a informar a la demanda sobre los procedimientos comerciales en su área, lo que dio como resultado que con el paso del tiempo tuvieran un consumidor "informado" y sabedor del tipo de productos que "explotarían en su paladar".

En dicho centro llevamos a cabo una serie de observaciones que no pretendían concluir en descripciones etnográficas ${ }^{2}$, sino solamente en descripciones reflexivas que, a partir de una serie de coloquios internos (del grupo de investigación), definimos como ejercicios de existencialismo cognitivo o reflexividad sociológica cuya fuente es la exposición del descriptor frente a una parcialidad de un universo de investigación amplio. En este sentido, nos expusimos a una parcialidad del universo de investigación llamado "las formas del comercio y la configuración social del consumidor" con la intención de describir lo que sucedía frente a nuestra mirada, considerando insumos reflexivos y cognitivos, producto de nuestra experiencia de vida y de investigación.

De esta descripción generamos tres narrativas o descripciones en las que destacamos algunos componentes que sobresalen en este tipo de centros comerciales, tales como la espacialidad, la sociedad, el significado y el consumo, los cuales se conjugan para crear un tipo de aspiraciones específicas. Por lo referente a la espacialidad, en las descripciones la abordamos en dos dimensiones: 1) como parte estilística arquitectónica de la metrópoli en su conjunto y 2) en la disposición del espacio interno para el paseo comercial. Respecto a la sociedad, hablamos no solamente sobre un tipo de consumidor, definido en términos de

\footnotetext{
1 Fueron muy pocas las noticias que sobre su apertura se hicieron.

2 La etnografía le ha costado mucho a la antropología en la medida que representa el método con el que investigó a la otredad, a la alteridad, antes llamada sociedad primitiva. Los estudios de algunos clásicos como Bronislaw Malinowski (1972), escrito originalmente en 1922; Evans.Prittchard (1977), publicado originalmente en 1940; Levi-Strauss (2011), escrito originalmente en 1955; Geertz (1997), escrito desde 1973, son algunos ejemplos, por citar algunos etnógrafos.
} 
la pertenencia a la clase social media y alta, sino también de las aspiraciones de pertenencia a dichas clases por parte de los consumidores que encuentran en la disposición espacial del centro comercial, las ocasiones para serlo, o aparentar serlo, o auto simbolizarse como parte de dichas clases por el hecho de asistir a tales lugares. Aquí se despliega el significado, es decir, las formas simbólicas de pertenencia a una elite de consumo, mediante la presencia en el lugar (como espacio lúdico para mostrarse), hasta el ser partícipe del consumo de marcas que llevan en su publicidad slogans de status y prestigios sociales. Por último, el consumo lo describimos con la liga de la oferta y la demanda. La oferta desplegada mediante una serie de estrategias publicitarias para seducir a la demanda y propiciar el consumo; mientras que la demanda movilizada por estrategias para lograr un fin que es acorde con las representaciones de status y prestigio. En este sentido, se trata de una serie de bienes simbólicos que manifiestan la hechura de una moda permanente $e^{3}$ en función de la pulsión de venta sin tregua.

De esta forma, el estudio de los centros comerciales o de la cultura del consumo moderno articula la espacialidad y el mercado mediante fórmulas de consumo simbólico que parten de "hacer creer" al consumidor que es precisamente mediante el consumo de dichos bienes como se está en condiciones reales de delinear y esculturar la personalidad (Douglas e Isherwood; 1990: Douglas, 2008), auténtica y original.

Visto así, el artículo lo estructuramos en tres partes, mismas que pretenden ir de lo general a lo particular: en la primera sección presentamos tres fragmentos de descripciones reflexivas, realizadas por cada uno de los autores, con la intención de delinear las formas que la oferta y la demanda adquieren en la espacialidad interna de estos centros comerciales y el impacto espacial metropolitano de las mismas; posteriormente adelantamos (presentamos) una serie de slogans empresariales y publicitarios que ilustren (presentan) las formas de seducción que propone la oferta y las maneras cómo la demanda se apropia de ellas en el contexto del consumo moderno; esto con la idea de ir delineando las formas culturales del consumo en la sociedad moderna, pero específicamente en la sociedad de Toluca. Al final hacemos nuestras conclusiones detalladas sobre esta seducción para el consumo y esta estrategia de lo obsoleto como bien de status y prestigio, es decir, como signo consumista de nuestros tiempos.

\section{En sus marcas: Descripción reflexiva. Uno}

Octubre de 2014. Nace en la metrópoli del valle de Toluca, acá en el altiplano central, un concepto de comercio moderno aglutinado en una forma arquitectónica bella y moderna, llamado Galerías Toluca. El silencio de su emergencia llama la atención en la medida que no hubo ruido, tráfico o noticias escandalosas sobre su creación, una especie de nacimiento silencioso que agarró a la mayoría de habitantes de esta metrópoli por sorpresa. En su nombre hay una marca que lo conecta hacia el pasado: Galerías Toluca es "tocaya" de Galerías Metepec, es decir, en sus nombres llevan definiciones como habitaciones largas y espaciosas con vidrieras, pilares y arcos. La ventaja comparativa de Galerías Toluca respecto de Galerías Metepec: la comida gourmet.

Desde la mejor intencionada mirada del planificador urbano esto representa un acto de justicia equilibrante en que el espacio de esta metrópoli encuentra, por fin, una balanza fuera del municipio Metepec ${ }^{4}$ : equilibrio y justicia; equilibrio en cuánto a que todas las

3 Una moda permanente es un oxímoron en el sentido que cualquier moda es una vanguardia que cambia, según indica la enseñanza de Baudelaire (Frisby, 1992) en función de consumir lo último, pero en la actualidad estamos en presencia de un mercado insaciable cuya pretensión es la ganancia a como dé lugar, de ahí que la vanguardia en la moda es tan fugaz como la seducción continua que genera el capitalismo para vender lo más rápido posible (Lipovetsky, 2011).

4 Metepec, es un municipio ubicado en el centro del Estado de México a un costado del municipio de Toluca, 
tiendas de este tipo de oferta y demanda se concentraron siempre en Metepec, y justicia en la medida que los habitantes de Toluca tienen acceso ahora a un centro comercial de estas características.

La historia de apertura de este tipo de comercios para sectores sociales de alto poder adquisitivo tiene su origen, al menos en el valle de Toluca, desde 1996 en que se creó Plaza Las Américas; posteriormente, en 1998, Galerías Metepec; en 2001 Plazas Outlet de Lerma; y en 2007 Plaza Sendero Toluca. Corren así 20 años de consolidación de este tipo de comercio de elite en el valle de Toluca, abarcando los municipios de Lerma, Toluca y Metepec con cinco establecimientos comerciales de este tipo. Sus antecedentes se encuentran en la misma entidad con Plaza Satélite, inaugurada en 1971, primer gran centro comercial de este tipo en México, dicho modelo se "desparramará" por todas las ciudades del país en una completa imitación de los grandes malls de los Estados Unidos y de Europa.

Plaza Las Américas posee un diseño arquitectónico tradicional alejado de la majestuosidad y gracia que posee Galerías Toluca, más bien se trata de un centro comercial que experimentó cierto decline ante la construcción de Galerías Metepec, allí junto a ella. Éste centro, Galerías Metepec, presenta una arquitectura cuyo eje es Liverpool y Sears, alrededor de ellos giran establecimientos que van desde tiendas de ropa, deportes, dulcerías, discos, software, restoranes y demás tiendas que ofertan a personas de poder adquisitivo alto, además de contar con un aglutinado de cines en la firma Cinépolis, verdadera ancla de atracción para los consumidores. Galerías Metepec es un galerón recto en el que todos los establecimientos están colocados en una línea en dos niveles. El flaneur paseante puede hacerlos primero en la planta baja y después en la alta. La oferta se presenta a su mirada en un mismo plano. Todos los que asisten allí a comprar se reconocen, al menos lo pueden hacer, como iguales o, mejor dicho, similares. Comprarán o venderán entre ellos. Ellos mismos pueden confundirse entre los que compran y los que venden. El sentimiento de seguridad que presenta el lugar es de destacarse. Los policías, vestidos de blanco, no llevan armas largas o sobre expuestas, por el contrario, parecen mansos, casi enfermeras, y uno no alcanza a distinguir las armas que se asoman en el pestillo del cinturón y la barriga.

En la segunda versión de Galerías, Galerías Toluca, sucede otra cosa. Para empezar allí sí hay policías que en las entradas cargan armas largas y a la vista de todos, no llegan a intimidar pero si a engendrar cierto estrés en el flaneur paseante. Dentro sucede lo mismo, los policías se encuentran por todas partes y sus armas se combinan con una mirada vigilante y sigilosa que termina por causar una pequeña incomodidad. La disposición de la seguridad es distinta en estos dos modelos de centro comercial para una demanda de alto poder adquisitivo. Y sin embargo con el paso del tiempo y en la medida que se fue llenando de compradores asiduos la policía se fue invisibilizando, como si la vigilancia del lugar de transfiriera a los usuarios consumidores.

La estructura arquitectónica es distinta. No se trata de un galerón sino de una estructura más compleja y más moderna. Por fuera parece un gran nido de aves, la madera simula estar estructurada por pequeñas ramas de plantas dispuestas en círculo, en forma de nido. Se trata de una forma circular con pocas salidas y distintas cámaras espaciales que separan a las personas. Acá el eje articulador de la experiencia comercial es Liverpool, pero este establecimiento aparece poco en el transcurso de la visita del flaneur, apenas asoma, reservándose para sí la más intensa de las experiencias comerciales, reservándose para darle al consumidor una extraordinaria sorpresa.

Cuando uno llega al lugar hay un poco de tensión dado el tráfico y la complicación que presenta, pues se encuentra en plena zona industrial de la metrópoli de Toluca. El estacionamiento es amplio y grande, y en cuanto uno llega a él de inmediato siente la sensación de descanso, en contraste con el afuera que es ruidos y denso de autos, fábricas y contamina- 
ción. Las puertas abren solas y el vigilante armado parece escanear a todos los que entran. Hay una primera sala grande desde la que se puede ingresar a Liverpool, del lado izquierdo los establecimientos se pierden ante la curvatura de la arquitectura. Sigue uno de frente y se abren otras puertas de cristal, allí los helados Hagen, los nutrisa y el café cielito lindo son la oferta, otra puerta de Liverpool del lado izquierdo y en él un restaurant argentino y de sushi. Se trata aquí de otro espacio cerrado, un espacio que controla la demanda, la atrapa, para seducirla. En medio de ellos, dos puertas laterales que conducen y conectan al estacionamiento en planta baja; luego otras puertas que se abren al paso tranquilo del flaneur. Hacia el lado derecho comienza la curvatura del círculo en dos niveles que anuncian la oferta con fotografías de modelos delgaditas y europeas. Uno puede decidir subir a la siguiente planta y llegar a una nueva sala; la comida rápida.

Todo parece estar construido para crear espacios cerrados con fronteras y límites, es como si se tratara de una arquitectura vigilante capaz de encerrar (y atrapar) a los consumidores. Parece un diseño arquitectónico cuyo paseo flaneur es un tanto conductista en el sentido que se está obligado a entrar a las distintas cámaras espaciales con las que está construido. Hay una especie de pulsión vigilante en la arquitectura que es fácil sentir como una evaluación permanente a nuestro consumo. Uno se siente vigilado no solamente por la cámara que uno sabe está dispuesta en algún lugar, sino fundamentalmente por la disposición del espacio que desde la entrada lo atrapa, lo envuelve, a uno. Es el espacio mercantilmente dispuesto para abrazar al potencial consumidor.

Hay allí, junto a la comida rápida, unas escaleras eléctricas que a cada instante llaman la atención, como si invitaran seductoramente a ser usadas. Desde la perspectiva del consumidor de alimentos rápidos las escaleras son persuasivas porque llevan hacia arriba y no paran de moverse hacia las alturas, hacia un mundo que termina cortado por el techo pero que abre cualquier posibilidad para quien se atreva a subirlas. Uno se mete a ellas y descubre que son unas escaleras eléctricas muy grandes. Paulatinamente el mundo de la comida rápida se pierde y la sensación de que uno está en un espacio transitorio (un elevador, una resbaladilla, una cámara de dispersión de partículas, un tobogán, una máquina del tiempo, etcétera) se vuelve emocionantemente placentero. La salida de las escaleras se acompaña de un policía débilmente armado, lo que contrasta con los de abajo. El cielo azul se convierte en el punto de llegada, pues una nueva cámara espacial atrapa a los flaneurs en un espacio completamente lúdico en el que se venden salchichas asadas para consumir en pequeñas mesas con sus respectivos paraguas o parasoles. La sensación del consumo se vuelve completamente lúdica pues proyecta, en un escenario comercial y público, la emoción de estar en un asado familiar, pero aquí compartiéndolo con extraños y desconocidos cuya intención es el consumo. La sensación de familiaridad entre consumidores similares tiene un efecto emotivo de sumo placer, pues se exalta lo familiar en un ambiente de anonimato.

Después uno puede entrar a los establecimientos comerciales de alimentos gourmet. La disposición de los productos se encuentra organizada como un gran mercado tradicional fijo en que uno transita entre los puestos para escoger los alimentos que comerá. Mariscos, pasteles, comida mexicana, cerveza, vinos, pastas y pizzas son la oferta para degustar. Es Liverpool apropiándose de un concepto popular y haciéndolo gourmet. El primero de este tipo en el valle de Toluca. Uno sigue atrapado en esta cámara espacial. Para salir de ella hay que entrar a la tienda Liverpool y uno deduce que el espacio está hecho para transitarlo en un solo sentido, un sentido comercial funcional que pone al flaneur en una obligada contemplación y expuesto a la seducción por adquirir algún bien, pues siempre queda la pregunta sobre cómo se vería uno con esa mercancía colgada al cuerpo, con esa fragancia untada o con esa prenda puesta.

Se trata de un sentido estético en que el consumo se vuelve un juego permanente; un sentido de espacio público/privado vigilado fuertemente para lograr la tranquilidad del flaneur; un sentido social en la medida que cada espacio cerrado puede clasificar incluso a la 
demanda en función de su poder adquisitivo; y un espacio de una moral clasista en la que se indica que cada consumidor decide en qué "corral de consumo" concentrarse o encerrarse, por lo que muchos de ellos no serán lugares para estar sino sólo para atravesar en lo que se llega al lugar propio de dicha distinción. El sentido lúdico de este transitar comercial se siente con mayor fuerza cuando termina de recorrerlo, pues queda la sensación de que se debe regresar a la ciudad real, la del espacio público altamente transitado, peligroso, sucio e inseguro; se proyecta así, en el uso de sus interiores, una vivencia liminoide, en el sentido de Turner (1992), que contrasta con la fuerza de lo real que regresa súbitamente.

\section{Listos: Descripción reflexiva. Dos}

\section{El matiz arquitectónico}

Cuando observé por primera vez Galerías Toluca, lo que más me impresionó fue el matiz moderno con el que se levanta, entre minimalista y naturalista. Impresión que más tarde se engrandeció ante el hecho de que el negocio central (Liverpool), a partir del cual giran otros locales de menor envergadura, tiene un sello particular: el gourmet. Esto lo convierte en el único mall del valle de Toluca que exalta las temáticas relativas a los alimentos y a la socialización para una clase social en particular. Este asombro inicial me llevó a plantearme una serie de preguntas como las siguientes: ¿para qué tipo de personas está pensado este lugar?, ¿por qué lo ubicaron en el sitio dónde se encuentra?, ¿qué implicaciones futuras puede tener para la zona inmediata o cercana? Por lo que respecta a la primera pregunta, una de las respuestas hipotéticas que hasta el momento he aventurado es la siguiente: el gran establecimiento comercial está pensado para personas de clases medias altas y altas de la región. Lo cual incluiría a habitantes de las zonas exclusivas de Metepec, de la zona poniente de la ciudad de Toluca (como Zamarrero en Zinacantepec) y algunos otros habitantes de los fraccionamientos cercanos con cierto poder adquisitivo (como el fraccionamiento Santa Elena, de San Mateo Atenco). Por lo tanto, y por exclusión, es un centro comercial pensado para no incluir a los estratos pobres o de menor rango, que estarían imposibilitados de adquirir algún producto o servicio ofertados por sus tiendas. Esto incluso parece visualizarse con el hecho de que las principales entradas a él están acondicionadas para automovilistas, antes que para transeúntes.

Su fisonomía moderna también se observa en algunos detalles arquitectónicos que parecen resistir la fuerza de la gravedad, al tiempo de recordar el dominio del hombre sobre la naturaleza. Ejemplos de ello son los techos de tubos tensados por alambres que sostienen grandes lonas de material industrial, sin que los mismos lleguen al suelo. De la misma forma se muestran los espacios de comida elevados donde aparecen pequeñas zonas de áreas verdes puestas en pisos altos. Este dominio se intensifica más con la existencia del gourmet que desplaza el consumo de alimentos por necesidad biológica por un simple capricho por degustar.

No puede omitirse, la simbiosis planeada entre metal y vidrio (o si se quieren palabras más acordes con el contexto; entre cristal y acero), que aparecen por distintos lugares del mall: desde los espacios particulares de las escaleras eléctricas, hasta los lugares de comida y exhibición de productos. Esto hace aparentar al mall como una estructura futurista, pulcra y trasparente. Y en tanto transparente, en constante vigilancia por cámaras de circuito cerrado que dan la impresión de haber logrado lo que parecía ilusorio hace algunos años: sustituir al personal de vigilancia, por métodos electrónicos más efectivos y menos onerosos.

No puede omitirse el hecho de que en sus paredes blancas normalmente se retratan figuras de personas que lucen productos ofertados. Figuras que, por cierto, parecen descontextualizadas no sólo del escenario local, sino también nacional, en tanto salen del estereotipo clásico del mexicano. 
En referencia a la pregunta de por qué se ubicó el mall en el lugar donde se encuentra, la respuesta que aventuro es que es por una cuestión económica y política. Por lo referente a la razón económica, el sitio puede representar un lugar accesible donde pueden confluir los tipos de personas mencionadas previamente, sin privilegiar a alguno de los anteriores como lo han hecho los malls cercanos. Por otro lado, en lo que respecta a la razón política, puede representar el ejemplo de cómo un mall puede ser permitido en un lugar que para los ojos de los urbanistas pueden no ser sustentable en términos ambientales, pues uno de los efectos más claros que ha generado en la zona es el tráfico en diferentes horarios y días que evidentemente puede generar smog, ruido y contaminación de otro tipo. Pero también, y sobre todo, porque parece mostrar lo que se vislumbraba hace algunas décadas: la creación de una gran megalópolis, incentivada por los gobiernos locales y nacionales.

Finalmente, en relación a la pregunta de qué implicaciones futuras puede tener para la zona inmediata o cercana: hasta el momento se observa un tráfico exagerado en determinadas horas y días de la semana. Esto afecta indudablemente a los habitantes del valle de Toluca, pero sobre todo a los más pobres, en tanto ellos son quienes normalmente utilizan el servicio público urbano que circula por las carreteras laterales. Pero también se puede intuir una especulación de los terrenos aledaños de los sectores más pobres quienes, ante la impresión de una mejora en el precio de sus tierras, pueden dejarse seducir por diferentes inmobiliarias que hacen de las zonas nuevas espacios habitacionales o de servicios.

\section{Los productos que se ofertan}

Ahora, ya estando en el mall, puede percibirse una trasposición de productos de otros mercados tradicionales o fijos que se transmutan en ofertas de exclusividad dentro de este lugar. Aquí, por ejemplo, se pueden encontrar dulces clásicos de los mercados aledaños pero dispuestos en formas específicas y envolturas sofisticadas que realzan su valor; asimismo pueden localizarse perfumes, videos, bebidas, que se pueden encontrar en otros sitios pero aquí están expuestos en estanterías singulares que le dan un toque de distinción. Claro, si se compara con lo ofertado en un mercado tradicional, aquí el número de estos productos es muy reducido, aunque ello parece responder más a una lógica comercial que a desabasto, pues se ofertan sólo los productos que son considerados indispensable para las necesidades de un tipo de clase particular, las clases altas, cuyo consumo normalmente es reducido en cantidades.

La trasposición de productos también se observa implícitamente en algunos bienes sofisticados que se ofertan, los cuales son presentados con características singulares para determinados clientes para darles un valor agregado, como son los alimentos con sellos calóricos. Finalmente dicha trasposición se refleja, aunque de forma menos clara, en la exhibición que se hace de distintos productos, algunos de los cuales son mostrados como si fueran típicos de alguna región, aunque en cantidades mínimas comparadas con las que pueden obtenerse en comercios populares y otros más renombrados de una forma particular para presentarlos como de clase.

No se puede negar que paralelamente a esta transmutación de productos hay unos que sólo se encuentran en este lugar y que parecen ir en contra de la lógica mercantil: pues en lugar de estar pensados para el consumo de masas, parecen estar hechos para algunos cuantos. Ejemplos de ellos son los productos de tecnología incorporada (como los automóviles), los cuales, si bien ofrecidos a cualquier cliente deambulando por el mall, son pensados específicamente para los de poder adquisitivo amplio, quienes dados los precios estratosféricos, podrían adquirirlos.

\section{Los consumidores que atrae el mall}

Finalmente, parecido a lo que ocurre en otros malls, en éste transitan al menos tres tipos 
de consumidores: los consumidores de productos necesarios, los consumidores por socialización y los consumidores de imágenes. Los consumidores de productos necesarios son aquellos que acuden al lugar para adquirir productos que parecieran ser de utilidad. Entre los productos que consumen aparecen alimentos bajos en calorías, videos, regalos, etc. Lo llamativo en este tipo de consumidores es que por medio de tales productos pretenden mantener un estatus que se atribuyen por el mismo hecho de consumirlos. Dentro de ellos destacan familias nucleares y algunos grupos de jóvenes. El segundo grupo de consumidores está conformado por aquellas personas que acuden para consumir no tanto como un fin sino como un medio, es decir, para hacer relaciones (de amistad, de cortejo). Sin ser una regla, gran parte de estas personas son jóvenes que se ubican en zonas de comida o bebidas, donde aparecen distintos tipos de rituales de interacción, como diría Goffman (2005). Rituales que, entre otras cosas, buscan afirmar la clase a la que pertenecen y el tipo de vida que acostumbran. Es de destacar que entre estos consumidores hay una transposición de prácticas consideradas naturales de otros contextos urbanos al interior de mall, por ejemplo, el festejo de un cumpleaños. Finalmente, el tercer grupo de consumidores es aquel grupo que acude con sentido de curiosidad o de conocimiento del mismo. Este grupo, antes que pretender consumir productos busca consumir imágenes o ideas que el mall proyecta.

Por otro lado, es importante mencionar que, si bien la mayor parte de los consumidores (de los tres grupos) son personas que parecen tener recursos económicos más que suficientes, existen algunos grupos de jóvenes e incluso familias que parecen no contar con grandes cantidades, lo cual, puede interpretarse desde dos ángulos: por un lado, como una muestra más de resistencia de los grupos menos pudientes para internarse en este mall exclusivo, conocerlo y transitar por sus espacios, sea para decir: "ya lo conozco", "ya sé cómo está", o simplemente para desengañarse ellos mismos y que "no les cuenten"; y por otro lado, puede interpretarse como una acción que muestra que el mall, aunque está pensado para un grupo particular de personas, es una membrana permeable a las clases sociales.

\section{Fuera: descripción reflexiva. Tres}

El valle de Toluca, en su trayectoria histórica económica, ha sufrido constantes cambios. En un inicio las actividades lacustres predominaban: la pesca, la captura de aves, la elaboración de productos del tule, significaban algunas de las principales actividades económicas del lugar; durante su evolución el valle fue el primer punto en América Latina donde se introdujo el ganado mayor, así, la actividad ganadera fue de vital importancia, destacando la elaboración de embutidos. De esta manera, los jamones y chorizos que caracterizaban al valle, junto con la barbacoa de res, otorgaban personalidad gastronómica, económica y singular a este valle. Surge así la siguiente pregunta: ¿la creación de un tipo de comercio moderno y globalizado, afecta de manera directa esta singularidad en la medida que sus productos responden más a consumos homogéneos y globalizados?

Otro cambio significativo que ocurrió en el valle de Toluca fue la introducción de industrias, en la primera mitad del siglo XX, dotando de importancia a las compañías cerveceras, jaboneras, harineras y ladrilleras, que brindaban a la ciudad un paso hacia la transformación de las actividades económicas del valle en su conjunto. Es en el año de 1952 donde la extracción y conducción de agua potable del valle de Toluca hacia el valle de México, cuando la transformación ocurre de forma tajante. Al mismo tiempo, la construcción del corredor industrial Toluca-Lerma otorgaba una nueva personalidad a las actividades predominantes del valle, (principalmente a la agricultura) pues la industrialización del valle ocurre como un motor tajante que refuncionaliza las actividades económicas. Es en este punto donde las actividades de la industria de la transformación propician una reestructuración de las actividades económicas, impactando de forma directa en la dinámica de la sociedad, que se expresará en la creación de nuevas colonias de habitación para los trabajadores de estas 
industrias.

Durante la década de los ochenta y más específicamente en el año de 1985, una gran parte de habitantes de la Ciudad de México se mudó a distintas zonas alrededor de la metrópoli de Toluca. Esto propició un intercambio cultural entre estilos de vida citadinos y los propios de la ciudad de Toluca con tintes de tradición pueblerina. Es a través de este intercambio donde se generan nuevos espacios de interacción y entretenimiento. Se desplaza el entretenimiento de la ciudad centro de Toluca (el acto de "pasear en los portales" queda reducido a los sectores populares y el surgimiento de las plazas comerciales llega para diferenciar los estilos de vida). En este proceso queda claro que Plaza Acrópolis (instalada en el centro de la ciudad en 1996) surge bajo este concepto, en un espacio no más grande al de una cuadra del primer cuadro de la ciudad, en que se desarrollan las principales actividades de distinción de "clase" entre los habitantes de la ciudad de Toluca, convirtiéndose en un nuevo parámetro de convivencia que permitía el goce similar (aunque no comparado) con las grandes plazas comerciales de la Ciudad de México. De esta misma manera, Plaza las Américas, ubicada en el municipio conurbado de Metepec y construida en el mismo año, potencializa la experiencia de convivir en una plaza comercial, en un lugar más amplio, con cuatro cines en un principio, en una sola planta, con áreas de un solo nivel donde las personas interactúan en la evolución de la vía que marca un Mall. A la postre o en dos años más, a un costado de Plaza las Américas, surge Galerías Metepec.

El concepto de Gran Mall llega al valle de Toluca dando a los usuarios la experiencia de deambular, bajo un mismo techo, en cines, restaurantes, comercios, una pista de hielo, tiendas de renombre. La experiencia de experimentar un espacio exclusivo, donde los usuarios deambulan, reitero, de un lado a otro observando aparadores, a las demás personas, en el mismo acto irreflexivo nombrado como consumo exclusivo. Fruto del crecimiento de la ciudad, de la novedad, de la teatralización de lo novedoso y lo exclusivo, se construye Galerías Toluca como un reflejo de las actividades y diversificación de consumo de la ciudad de Toluca.

Galerías Toluca se encuentra al límite del corredor industrial más importante del valle. Se trata de una reestructuración y reutilización del espacio (uso del suelo mixto). Así, las que hace cien años eran tierras de las haciendas existentes, se constituyeron en corredor industrial, y éste dio entrada a los servicios y al comercio. Sobre la avenida Tollocan se encuentran como mudos testigos la empresa Pfizer, la Nestlé, dos de las empresas más importantes en su ramo. Ahora también se encuentra en el mismo espacio una universidad privada, un museo, un boliche y las instalaciones de la secretaria de economía del gobierno estatal.

Este nuevo referente de plaza comercial convive con elementos industriales; con pequeños puestos de comida para los trabajadores de las fabricas existentes; con el olor a la industria; con el aroma del café y del chocolate de la Nestlé; con los ruidos lejanos de la industria y el panorama que conjugan a los antiguos cascos de las haciendas; los estacionamientos, los tráileres estacionados $\mathrm{y}$, culminando con una plaza moderna que brinda un aire cosmopolita a la zona. En ella se encuentran estacionamientos escalonados con identificadores en números y letras que nos llevan del gris mundano donde se estacionan los autos al domo de la luz, que permite la exposición a una experiencia más cercana a estar en el sol, perdón, quise decir estar en el centro comercial.

Caminantes elípticos que esperan observar a la plaza en todo su esplendor, con tiendas abiertas, con marcas esperadas. El recorrido funciona recorriendo los pasillos, vuelta tras vuelta, el movimiento de traslación del usuario, con pequeñas estaciones para el reposo, sillones, periódicos, propaganda, significa descansar para seguir caminando sobre los pasillos. Es sobre ellos que se encuentran las distintas marcas de ropa, joyería, juguetes y demás productos. Siguiendo este recorrido elíptico se encuentran otras escaleras que te permiten subir al siguiente nivel para transitar nuevamente sobre otro movimiento de traslación. En 
uno de los extremos se encuentra la zona de alimentos, diseñada para que los usuarios puedan comer en mesas y sillas de colores, culminadas con un gran ventanal al fondo. En este lugar se encuentran las principales empresas de comida rápida, la industria alimenticia masificada, ese es el mensaje que contrasta con un gran elevador en otro extremo que nos conduce únicamente en una dirección, hacia arriba, un túnel se recorre en un lapso de 20 a 30 segundos y te lleva a un nuevo nivel, cuando piensas que todo ha terminado, hay más, te lleva a una nueva experiencia que realza y separa las condiciones de los otros (Bauman, 2004) es la zona gourmet, donde a diferencia de la zona de comida rápida, el producto es "más fresco", más novedoso", "preparado en el instante" en que puedes elegir.

Esta experiencia conduce a las personas a una sensación mayor de exclusividad, es la cúspide del centro comercial, se dejan atrás los recorridos elípticos para llegar al cenit de este conglomerado, te encuentras en la zona más exclusiva, el camino sólo fue en una dirección, círculos, círculos y después: subir. Es un concepto novedoso, un concepto rescatado de lo considerado" mercado alternativo (pues en un mundo industrializado, homogéneo, la única forma de existir es ser diferente, comer diferente, vivir diferente). Esta es la percepción que moldean este tipo de estructuras, te trasportan temporalmente a otro lugar, te separan de los demás, ya eres ajeno a la industria, a las haciendas, a la calle, al propio centro comercial, te encuentras inmaculado, en el punto más alto donde sólo algunos llegaron, y a manera de Bauman (2004), solo sonríes, interactúas con una cordialidad indiferente, un intercambio de miradas (nada que ver con un mercado tradicional) "buenos días, buenas tardes, cual es el precio, ¿que me recomienda?" Son sólo algunos de los parámetros permitidos para la interacción.

La experiencia dentro de la plaza comercial sucede a modo de experiencia grata para todos, todos son iguales, clientes, consumidores u observadores, mientras se mantenga el orden y la dinámica de girar en torno a los aparadores, las personas se convierten en una misma representación, la sensación del ser igual. Sin embargo, las diferencias ocurren al momento de ocupar espacios, preferir algunas marcas sobre otras, consumir estos productos y no otros; la diferencia radica en el consumo y en el gasto, existe así una generalidad o igualdad de circunstancias para los que deambulan, y a la postre las diferencias se establecen con el consumo y la cantidad de consumo; dicho de otra forma, los estratos sociales no existen al margen de quiénes transitan, todos son iguales, son clientes, la diferencia radica en el gasto y la preferencia de un producto sobre otro, es decir, en la intimidad del producto elegido, pero este gusto no se muestra.

Sólo existe una dinámica de intercambio en este lugar y ésta está basada en la lógica de la pureza del dinero (Simmel, 1977), por lo tanto, el orden centrado en los parámetros culturales y de significado que delimitan el "buen gusto", que proyectan "la apariencia", delinean una estética y regulan la conducta. En estos espacios se prohíbe gritar, correr, regatear, bromear y transitar sin orden, como ocurre en un mercado establecido o en un tianguis ${ }^{5}$. En estos espacios se obliga uno a autocensurarse. El propio edificio o estructura moldea las pautas de comportamiento de las personas que ingresan en su interior, a ello hay que sumarle los distintos dispositivos, como las cámaras o los miembros del cuerpo de seguridad, que regulan la presencia de los otros en un mundo de similares.

Llegar a Galerías Toluca puede ser relativamente sencillo, puedes llegar en auto, o bien sobre la avenida Tollocan, sobre esta avenida transitan los autobuses locales y foráneos que parten desde Lerma; Santiago, Ocoyoacac, Atarasquillo, San Pedro Tultepec, Distrito Federal, Metepec, La Pila, Infonavit San Francisco, entre otras. Esto sugiere un tránsito mayor de personas que ocasionalmente se convertirán en consumidores de esta plaza comercial. El espacio, de esta manera, es atravesado por los distintos puntos de interacción, de orígenes,

5 Tianguis refiere a un mercado itinerante que se coloca en alguna zona en un día a la semana. Su origen es prehispánico. 
vecindades y colonias diversas. Así en esta otredad de otros, las personas confluyen con distintos grados de interés, distintos grados de confianza y desconfianza y distintas gradaciones de pertenencia a una clase social dada que se camuflea en el uso de todos en estas plazas.

La indiferencia se articula como la base de convivencia, a manera de código no escrito, que regula normas. Existe cierto grado de aceptación cuando comparten el mismo espacio de comercio; se proyecta un código de tolerancia en el que guardar las apariencias es el objeto final de esta experiencia.

\section{Semántica del comercio en los centros comerciales}

Más allá de las diferencias en las descripciones anteriores, derivadas tanto de las formaciones como de las experiencias vitales de cada uno de los autores, las tres encierran algunos aspectos coincidentes que pueden enumerarse de la siguiente forma:

- la articulación de este tipo de complejos comerciales con el entorno externo que es la metrópoli y los cambios sociales que se generan a partir de nuevos estilos de consumo

- la espacialidad interior del complejo, como escenario propicio que vincula la experiencia del paseo y el comprar placentero

- las estrategias de la oferta para seducir a la demanda mediante publicidad que engarza significados de distinción, originalidad y autenticidad entre personas autorepresentadas como similares.

Pero, ¿a qué remite cada uno de ellos?

\section{Centros comerciales modernos y metrópoli}

El primer aspecto remite a la idea de que los centros comerciales como Galerías Toluca, se articulan con la dinámica metropolitana que se vive desde hace algunos años en el valle de Toluca, la cual, a su vez, es parte de una lógica megalopolitana. En efecto, como lo señalan algunos estudios, la historia de los centros comerciales en este valle se remonta a la década de los noventa del siglo pasado en que se empieza a experimentar una dinámica metropolitana. Una dinámica que se concretiza en una nueva fisonomía urbanística que trae consigo la emergencia de nuevas rutas y construcciones, y que paulatinamente va modificando las dinámicas sociales, incluyendo las de consumo.

Esta dinámica no se experimentaba en las décadas anteriores pese a la cercanía con la Ciudad de México, tan es así que los circuitos de mercadeo en el valle de Toluca se basaban más en un consumo más local y tradicional que moderno. Se trataba de un consumo que se edificaba a partir de los mercados tianguis, de itinerancia espacio temporal, los cuales se asentaban y se siguen asentando en distintas zonas de la ciudad de Toluca. El más emblemático es sin duda el desplazado mercado Juárez que se instalaba junto a la terminal de autobuses. El consumo también se edificaba a partir de los mercados tradicionales fijos organizados en cajones que ofrecían y ofrecen mercancías, desde frutas y verduras hasta juguetes, pasando por flores, abarrotes y todo tipo de chiles y granos. Estas dos modalidades de mercadeo o comercio implican la existencia de un punto de surtimiento representado por la central de abastos, es decir, los productos agrícolas llegan a dicha central y de ahí los comerciantes la adquieren para luego expenderla en sus cajones o puestos. Lo importante a destacar es que estos productos se articulan estrechamente con el productor de bienes y en muchos casos con el campo, con las actividades agrícolas y de recolección ${ }^{6}$.

6 Los bienes de recolección son las zetas, los hongos, los quelites, los capulines, los chabacanos, algunos tipos de durazno, quelites y hasta charales y ranas que son vendidos sobre todo en los mercados tianguis y que representan una posibilidad de intercambio mercantil entre los bienes que se generan en distintos pisos ecológicos. Desafortunadamente este tipo de intercambio está en peligro de extinción en la medida que los ambientes naturales están siendo destruidos y los conocimientos sobre los alimentos sustituidos por fórmulas eminentemente 


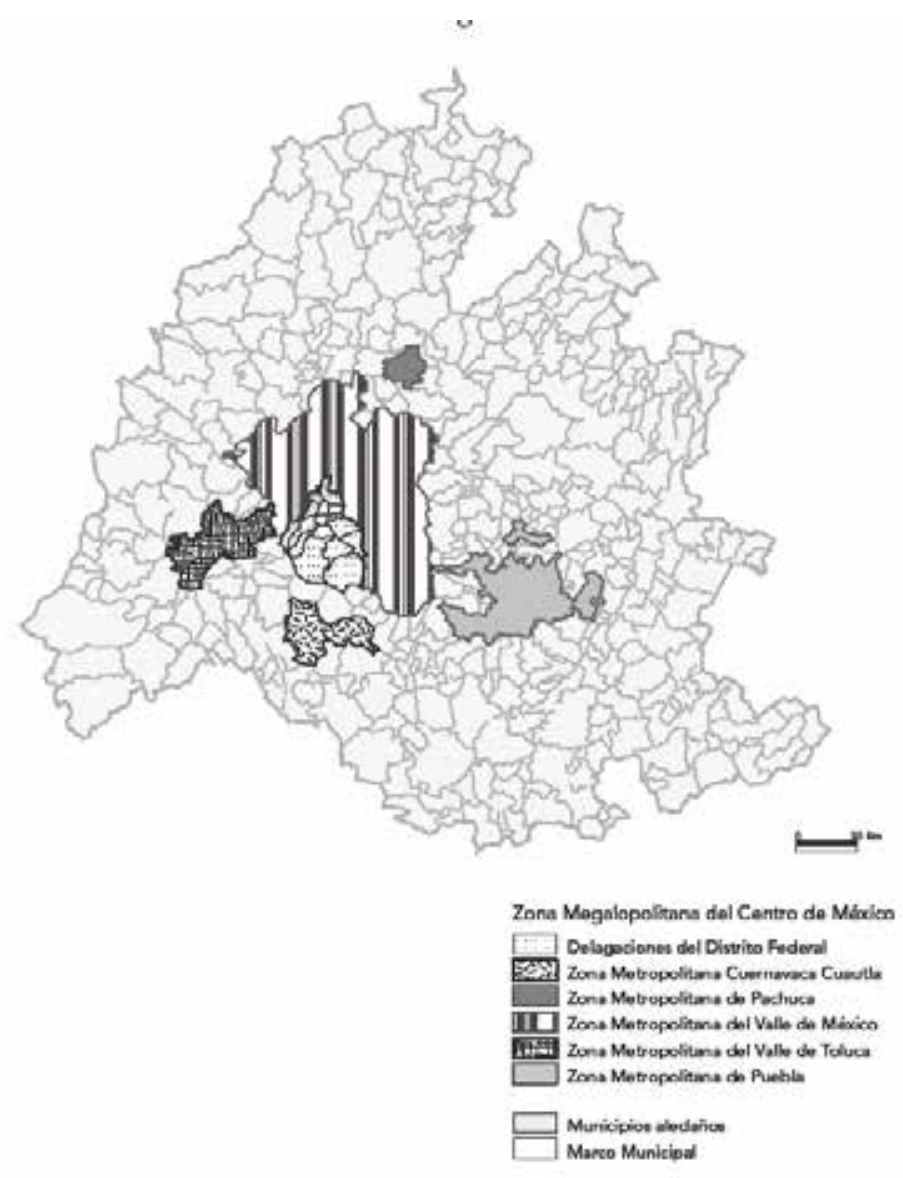

Felipe Gonzalez: Ortix [2000].

Figura 1

Pero a partir de la década de los noventa esta dinámica se transforma, pues empiezan a emerger los centros comerciales que traen consigo otras modalidades de consumo moderno, que vienen impregnados de significados culturales. Estos centros comerciales grandes aglutinan establecimientos marca que se presentan como una unidad de oferta a una demanda "tratada" como una elite.

No obstante, como el proceso metropolitano del valle de Toluca comenzó con la integración de la industria en zonas rurales, estos centros comerciales se establecen en espacios en donde el mercado de trabajo y la agricultura conforman dos actividades que se complementan en la lógica de vida difusa (Nivón, 2003) que proyecta el espacio megalopolitano. Es decir, se ubican en espacios donde no se separa el campo y la ciudad sino más bien en donde se desarrollan los dos tipos de actividades. Ello no es óbice para que algunos de ellos, empero, utilicen propagandas modernas para promocionarse en sus espacios y más allá de ellos. Por ejemplo, en la ocasión de los primeros días de la plaza comercial Outlet Lerma (inaugurado en 2001) se anunciaba como el Outlet Ciudad de México y luego enfatizaba la publicidad, a 15 minutos de Santa Fe, dando a entender que esta propaganda ya marcaba un sentido megalopolitano que vincula y estrecha a dos metrópolis ${ }^{7}$, la de la Ciudad de México 


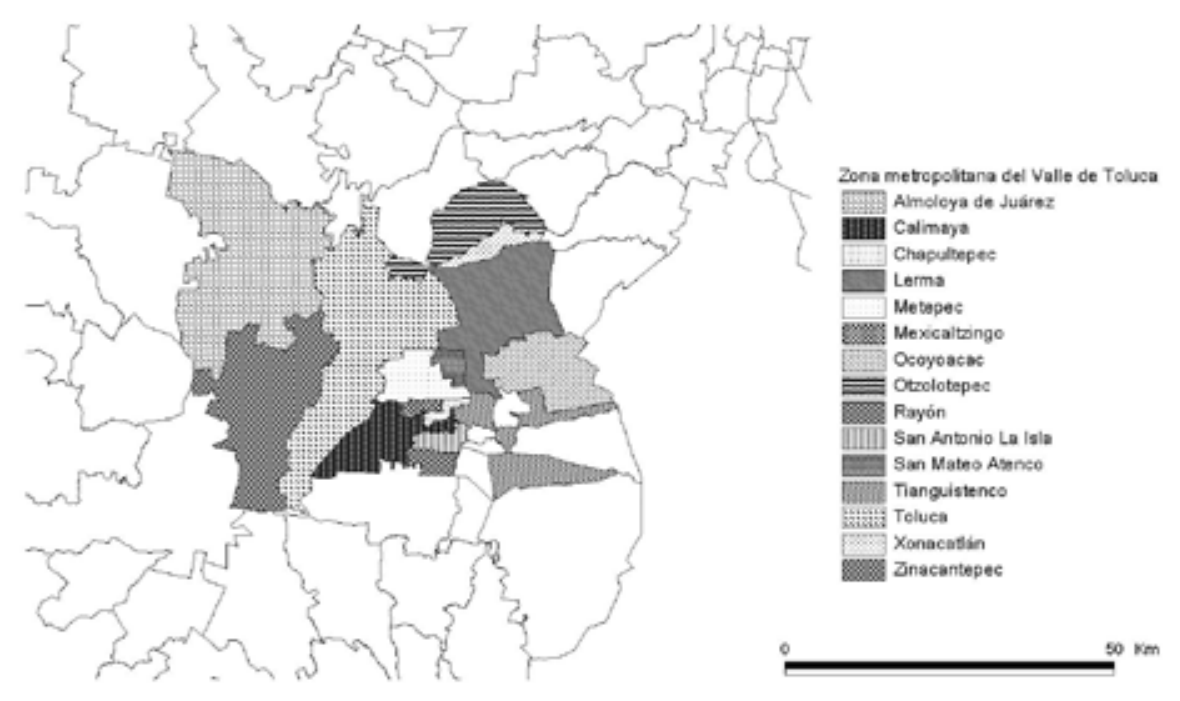

Figura 2

y la del valle de Toluca. Metrópolis que, por cierto, como muestra la figura 1, forman parte de la megalópolis del centro del país, cuya preeminencia la tiene la metrópoli del valle de México sobre las metrópolis del valle de Toluca, de Cuautla - Cuernavaca, de Pachuca y de Tlaxcala - Puebla.

Esta ubicación de los centros comerciales en tales espacios si bien podría resultar criticable en el valle de Toluca, dadas las diferencias que existen entre los municipios que conforman la zona metropolitana (Figura 2), parece seguir una tendencia irreversible, en tanto aparecen constantemente en diferentes municipios constituyentes de ésta.

Por citar sólo algunos ejemplos, los centros comerciales de dimensiones grandes que se han instalado en la metrópoli del valle de Toluca en los últimos años son las siguientes:

\section{Plaza Las América. Fundada en 1996. Municipio de Metepec \\ Plaza Galerías Metepec. Fundada en 1998. Municipio de Metepec \\ Plazas Outlet Lerma. Fundada en 2001. Municipio de Lerma \\ Plaza Sendero. Fundada en 2007. Municipio de Lerma \\ Plaza Galerías Toluca. Fundada en 2014. Municipio de Toluca}

Por su parte, otras plazas comerciales de menores dimensiones que han venido emergiendo para el comercio de bienes de consumo moderno asociadas a los anteriores son estas:
Almoloya de Juárez:
Plaza Sophia
Plaza Comercial Juárez
Lerma
A precio Lerma

adquiere esa distinción conceptual cuando incorpora una unidad territorial y administrativa distinta a la de su origen; una megalópoli se define por la articulación entre dos o más metrópolis (Garza, 2000). 


\section{Metepec \\ Pabellón Metepec \\ Plaza Península \\ Plaza San Juan \\ Plaza España \\ Plaza Izar \\ Plaza Aranjuez \\ Plaza Las Fuentes \\ Plaza la Pilita \\ Town Square Metepec \\ Toluca \\ Gran Plaza Toluca \\ Acrópolis}

La figura 3 muestra la distribución espacial de todas las plazas de comercio moderno que existen en la zona metropolitana del valle de Toluca. Lo importante a anotar es que la presencia de esta modalidad de consumo se está diseminando a lo largo de la metrópoli de Toluca, lo cual implica no sólo el cambio de fisonomía de la urbe (calles orientadas hacia el centro comercial, tráfico, arquitectura moderna en frontera con las humildes casas, usos del suelo mixtos, etcétera), sino fundamentalmente la conformación de un nuevo tipo social, consumidor de bienes globales que cargan en ellos significados asociadas más allá de su valor de uso, para usar una vieja hipótesis, manifestada desde 1972, de Jean Baudrillard (1989). De esta forma, el mensaje arquitectónico y la diseminación metropolitana de estas plazas comerciales refiere a una apertura de mercado para todos, es decir, aunque en el fondo se trate de un consumo exclusivo, el aparente mensaje de apertura total; todos pueden entrar a comprar, quien no lo haga será quien se autoexcluya; todos los bienes del mundo se encuentran concentrados en dichas estructuras arquitectónicas y comerciales. En estos 20 años desde la primera plaza se están configurando formas sociales diversas que subsisten

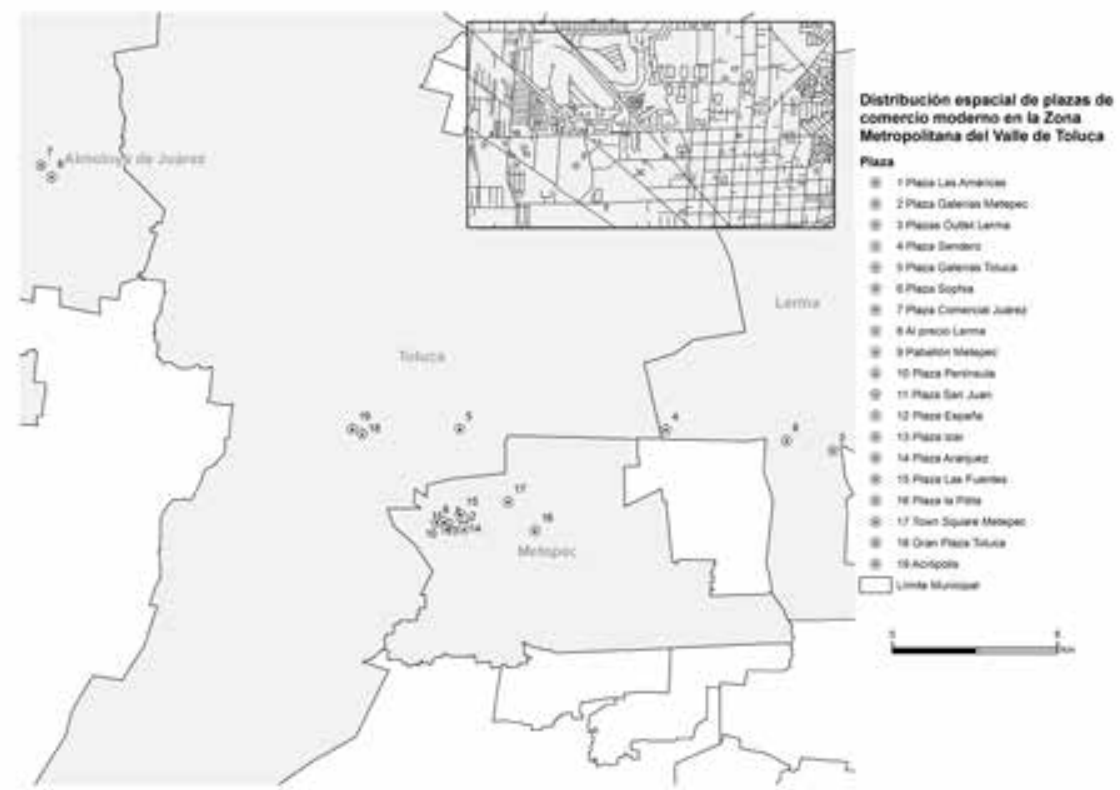

Figura 3 
con formas anteriores, también existentes en la zona metropolitana, según las describimos antes.

\section{El escenario propicio para el paseo y la compra placentera}

El segundo aspecto hace alusión, como lo indica las mismas palabras, a la idea de que el Centro Comercial, Galerías Toluca, es un espacio que vincula la experiencia del paseo y el comprar placentero. Pero, ¿por qué lo decimos? Por dos cuestiones principales: 1) porque el centro comercial dispone de una serie de bienes que al tiempo de evocar ilusión evocan distinción; y, 2) porque hace sentir como iguales a los diferentes que lo visitan. Veamos.

Por lo referente a la primera cuestión, vale recordar que en este centro comercial se dispone en sus interiores de una forma circular en que los bienes son mostrados espectacularmente. Ello para tratar de construir un escenario dispuesto para el consumo donde el comprador es el actor central de este acto. Las fronteras entre los espacios son transparentes y cada espacio es representados como un "cajón cerrado" de alternativas de compra, en donde se vive una experiencia "del consumo como espectáculo recreado en escenarios cambiantes" (Ramírez, 1998:323) y en donde las puertas con sensores son abiertas como si fueran telones de otros actos.

Pero en tanto escenario dispuesto para el consumo, la arquitectura del centro comercial también se convierte en una suerte de disposición vigilante que sigue al consumidor a cada paso que da. Disposición que evalúa el consumo que hace de los productos ofertados y que al mismo tiempo analiza las estrategias de persuasión comercial.

Por otro lado, por lo referente a que el centro comercial hace sentir como iguales a los diferentes, vale mencionar que todos sus usuarios son representados como similares, en tanto consumidores potenciales. De modo que en él, la aparente limpieza y el sentido de seguridad que genera el convivir "con similares", se proyecta un sentimiento general que implica poco esfuerzo por la convivencia con el diferente o el distinto. Esta facilidad para la convivencia y el minúsculo esfuerzo invertido en la interacción, se instala en cada persona hasta tal punto que ellas mismas se autocensuran; no se imaginan en una interacción de regateo, en una de negociación, mucho menos gritando, chiflando o corriendo. En este tipo de establecimientos "todos somos iguales" porque los parámetros de la interacción se reducen a la compra y la venta.

Pero hay aquí una tensión permanente en la oferta de estos bienes pues si bien el espacio arquitectónico invita a sentirse similares, las estrategias persuasivas para las ventas enfatizan la distinción y la diferencia. La espectacularidad para seducir a la demanda es como "un grito silencioso" expresado en las luces y los anuncios que parecen "gritar desde el silencio". De esta forma, se establece una complicidad colectiva entre los consumidores; se trata de consumos sentidos de elite (distintos para cada quién, hechos a la medida de la personalidad individual, acordes con las exigencias más elegantes, etcétera), pero masificados en la intencionalidad de lograr la realización de bienes la mayor cantidad de veces posible.

Por lo tanto, mientras la oferta establece una mercadotecnia en la que cada bien posee o carga mensajes para persuadir al consumidor, al mismo tiempo, en tanto se trata de implantar en el consumidor su pertenencia a una elite moderna, proyecta la similaridad como el componente clave de la estrategia de venta. Se trata de sentirse "diferente entre similares". La diferencia se inscribe en el hecho de consumir más o de consumir lo más novedoso, pues dejar de hacerlo podría representar dejar de pertenecer a esta elite de consumidores.

Dicho lo anterior, se puede señalar entonces que en estos centros comerciales todos somos consumidores; unos porque compran persuadidos de su gusto exquisito (los alimentos no están hechos para saciar el hambre sino para degustar el paladar); y otros porque consumen imágenes para hacerse una idea de cómo se plantea, desde esta oferta de mercado, el deber ser de la sociedad; sin embargo, en ellos también se plantean distinciones que se 
generan a partir del consumo de ciertos productos, lo cual, a su vez, genera una pulsión por comprar a cada instante.

\section{Ser auténtico y original es el objetivo}

Por último, podemos decir que Galerías Toluca posee una serie de tiendas que van desde ropa, electrónicos, zapatos, café, productos nutricionales, telefonía, juguetes, restaurantes y entretenimiento. Todos estos establecimientos comerciales poseen una estrategia de oferta para persuadir a la demanda que atraviesa por la publicidad del producto. En esta intención se construye un tipo de consumidor que aspira llegar a participar de las cualidades enunciadas en cada bien, en este sentido, el bien objetiviza mensajes que pueden realizarse consumiéndolos. El consumo de dichos productos se reserva a usuarios conocedores de sus "cualidades exclusivas" que construyen mediante mecanismos que se dirigen y orientan por la construcción personal de la autenticidad y la originalidad. Pensamos que estos dos objetos representan el componente más preciso del consumo moderno y de la modernidad que enaltece el individualismo; el sentido individualista se configura así en la forma o configuración más realizada cuando la autenticidad y la originalidad se convierten en el producto de las decisiones y elecciones "más acertadas" que hace el consumidor. La emergencia del dandy y de la moda responden a la posibilidad de elegir, con parámetros sentidos desde la individualidad. Y esto es posible sólo en la modernidad (Frisby, 1992: Simmel, 1988: Giddens, 2009). En esta suerte, los centros comerciales representan una plataforma para la posible realización de la autenticidad y la originalidad.

Las estrategias publicitarias que la oferta construye configuran un modelo de demanda, delinean aspiraciones y en esta intención terminan por educar al consumidor al tiempo que crean definiciones. Todo bien carga, además de su estructura material, una de tipo simbólico. Por ejemplo: "Un toque femenino y coqueto es un dije rosa", define el objeto y le asigna propiedades.

También existen los bucles publicitarios que parten de un reconocimiento dado a la persona, pero pretenden aumentar alguna cualidad con un accesorio, algo así como optimizar el estilo: "Agrega brillo a tu outfit (vestuario) con un accesorio, como este brazalete".

Pero incluso los bienes más útiles, ceden ante el mensaje que cargan: "Un detalle imprescindible es un cinturón para asegurar que el pantalón conserve su corte y lucir alineado".

Los mensajes asignados a otros bienes informan y aconsejan: "Transformará un estilo sobrio en un look más relajado con una mezcla de colores y patrones", según ilustra la marca de unas elegantes camisas. Bucles que aconsejan el consumo de servicios, ir al cine por ejemplo, recomiendan a las mujeres lograr "un estilo effortless (sin demasiado esfuerzo) con el cual parezcas arreglada pero natural, como si no te esforzaras demasiado"; y el consejo para los hombres es "estar cómodos pero con estilo". Hay una ligereza planteada en estos bucles publicitarios; el poco esfuerzo para lograr grandes logros; la arquitectura de los interiores; la proyección moderna que da a la metrópoli la estructura arquitectónica y la persuasión demandan conductas sociales de mínimo esfuerzo.

El uso del inglés mezclado en los bucles publicitarios le asignan al bien una cualidad extra; la de estar articulados de algún modo con lo global. De esta suerte, la cotidianidad en estos centros comerciales hace que el paseo y el consumo placentero sea una experiencia local de relaciones cifradas en patrones de consumo global.

\section{Conclusiones}

A partir de tres ejercicios de observación reflexiva en un centro comercial de consumo moderno de reciente creación, como fue el llamado Galerías Toluca inaugurado en octubre de 2014, desplegamos una serie de hipótesis y preguntas que se orientan sobre las formas sociales y culturales de sociedad que este consumo delinea y proyecta. En las tres descrip- 
ciones se aglutinaron temas comunes que vincularon la espacialidad, la sociedad, la metrópoli, el significado y el consumo.

Una ventaja de este estudio es que centramos la observación, desde el comienzo, en actividades de este centro comercial, lo que nos permitió calibrar las formas de aprendizaje e interiorización cultural de estos bienes en la sociedad, es decir, nos permitió ver cómo se fue configurando una sociedad de consumo en el contexto de la ciudad de Toluca, una metrópoli que se encuentra integrando a pueblos rurales (estilos de vida, gastronomías, actividades rurales, etcétera) y mantiene flujos urbanos diferenciados con los distintos municipios que la componen.

De esta manera, la espacialidad, según las coincidencias que las tres descripciones muestran, se define en dos ámbitos, en el exterior como forma de impacto al paisaje metropolitano y la disposición de los espacios al interior del mall. En lo que respecta a la primer dimensión, la arquitectura proyecta en la metrópoli un escenario que rompe con la industria y las avenidas repletas de autos; se trata de una estructura que aparenta ser el nido de alguna especie de aves pero al mismo tiempo como un estadio o un auditorio en el que se presentaran espectáculos de diverso tipo e invitan (persuaden) a las personas a salir de la cotidianidad, rígida y monótona, para entrar a un tiempo y espacio liminiode (Turner, 1992), es decir, fuera de los cánones de la cotidianidad, proyectando una experiencia profundamente placentera o hedonista. Con este tipo de arquitectura comienza la persuasión hacia los potenciales consumidores que, seducidos por la promesa implícita de tal espectáculo (sobra decir que hay ocasiones en que se presenta un concierto de violín o piano o la asistencia de un grupo de marionetas para niños), arriesgan entrar al establecimiento.

En lo que respecta al segundo tipo de experimentar la espacialidad, al interior del mall, ésta se presenta como una serie de cámaras continuas que se construyen a sí mismas como escenarios distintos que hacen sentir al consumidor como el actor principal de la puesta en escena de un drama; cada espacio se encuentra separado por detalles estilísticos que combinan el cristal y el acero que se mueve con sensores que "atienden" el paso del consumidor, como sí éste fuera la estrella principal de este acto, reiteramos, anulando toda posibilidad de esfuerzo por transitar de espacio en espacio implicados en estos interiores. Y es que nulificar el esfuerzo en su complitud significa proyectar la idea de que en estos interiores todos los consumidores son similares. Esta similaridad se sustenta en un sentimiento de pertenencia a una elite de consumo, pues estos centros comerciales pretenden delinear un consumidor de elite que sea capaz de valorar los significados asociados a los bienes (en esto consiste el principal aprendizaje que estos malls realizan con los consumidores). Se trata de un consumo de elite masificado, allí radica el sentimiento de pertenencia a este sector social de consumo.

Pero a la vez que dentro del mall se proyecta esta pertenencia de consumidores similares, hay una tensión permanente por lograr la distinción y la diferenciación de los demás en la medida que los bienes han objetualizado mensajes culturales que proyectan la originalidad y autenticidad de la personalidad individual y atomizada. En esto consiste el significado que cada bien carga en sí como el producto elaborado de la publicidad. Es decir, los bucles publicitarios se orientan hacia la distinción y la originalidad individuales en el momento que han delineado y definido su propia sociedad de consumidores: un grupo de similares pertenecientes a una elite de consumo esculturada/estructurada por la oferta. De esta manera, una vez que la demanda ha internalizado la pertenencia a este nivel de consumo, la estrategia de la oferta consiste en remarcar la diferencia y la distinción a través de bucles publicitarios que proponen un estilo individual mediante la búsqueda de la autenticidad y la originalidad.

Así, cada bien o producto no significa sólo un bien de uso y consumo sino en él van cargados muchos más mensajes que se adentran en el consumidor. Ahora el consumidor no busca, por ejemplo, calmar el hambre sino degustar placenteramente un sabor que le explota 
de distintas maneras según sea la parte gustativa por donde pasa el bocado; se consume un cinturón no para detener los pantalones y evitar un bochorno sino para mantener alineado el estilo de un pantalón de pinzas y de caída recta; se eligen los zapatos para la boda no en función de la seriedad y las proyecciones de felicidad que el evento en sí procura sino dependiendo si la boda se realizará en un salón, en una iglesia moderna o barroca o será campestre. El sentido de los mensajes que la oferta delinea y coloca en los bienes varía, pero fundamentalmente se basan en el estilo.

En este sentido, la oferta de estos bienes marca modelos de moda fluida para cada bien. Consumir estos bienes implica un conocimiento sobre ellos pues cada uno de ellos representa además un mensaje colectivo, un significado cultural, constituye en sí un elemento de un código más amplio cuyos mecanismos de comprensión se reservan a los similares que pertenecen a dicho grupo de consumidores que a la vez buscan la autenticidad en cada acto de compra.

En esto consiste el proceso de aprendizaje que pudimos observar en nuestras descripciones reflexivas; en saberse parte de un consumo de significados. De esta forma, la cotidianidad de las compras placenteras se convierte en una práctica cotidiana articulada a la economía global de los bienes pero también de los significados culturales modernos del mundo. En este sentido, la existencia de estos centros comerciales representa cambios en las formas sociales que se configuran en las regiones, en este caso en la ciudad de Toluca.

Ahora bien, por último, nos gustaría adelantar la idea de que estos bienes, al estar "envueltos" en significados y códigos culturales, se constituyen como modas. La oferta a final de cuentas requiere aumentar el consumo y mantenerlo permanente y una estrategia, además de la publicitaria, es hacer sentir en la demanda la fatalidad de producto, el término de un patrón de gusto colectivo, el final de la capacidad del bien por generar placer. A esto se le llama la estrategia de la obsolescencia planificada (Leonard, 2013). Cuando ésta se implementa en centros comerciales de consumo moderno (en otros niveles de mercado, como los súper mercados, se observa muy enfáticamente en las fechas de caducidad de los productos enlatados o empacadas, por ejemplo), se hace o transmuta en moda; es decir, se trata de bienes publicitariamente convertidos en símbolos, pero en dichos símbolos llevan también las marcas de su "fatal muerte", pues se encuentran en la lógica fluida y cambiante de la moda. Se internaliza así la obsolescencia en la demanda, en el consumidor como un sentimiento inevitable de pérdida de distinción y diferencia, es decir, de autenticidad y originalidad; una vez que la obsolescencia planificada haya internalizado en los consumidores se tiene garantizada la cultura del consumo, pues estos regresarán cuando sus bienes hayan dejado de generar placer y de encontrarse en el centro de la moda.

La cultura del consumo se encuentra en el centro de este tipo de sociedad. Se corre el riesgo de que el consumo se convierta en un fin en sí mismo y no en un medio para lograr otros fines. Una sociedad que consume por consumir es sin duda una sociedad que ha perdido o ha sustituido un proyecto de solidaridad por un individualismo perdido en la pulsión por mostrarse sin más objeto que el de mostrarse como lo hacen las vitrinas de los malls.

\section{Bibliografía}

Baudrillard, Jean. (1989). Crítica de la economía política del signo, Siglo XXI, México.

Bauman, Zygmunt. (2004). Modernidad líquida, FCE, México.

Benjamin, Walter. (2005). El libro de los pasajes, Akal, Madrid.

Douglas, Mary. (2008). Estilos de pensar, Gedisa, Barcelona.

Douglas, Mary y Baron Isherwood. (1990). El mundo de los bienes. Hacía una antropología del consumo, CNCA, Grijalbo, México.

Evans_Prittchard, E. E. (1977, Los Nuer, Anagrama, Barcelona.

Frisby, David. (1992). Fragmentos de modernidad. Teorías de modernidad en la obra de Simmel, Krakauer y Benjamin, Visor, España. 
Garza, Gustavo. (2000). “Ámbitos de expansión territorial”, en Gustavo Garza (coordinador), La ciudad de México en el fin del segundo milenio, El Colegio de México y GDF, México.

Geertz, Clifford. (1997). La interpretación de las culturas, Gedisa, Barcelona.

Giddens, Anthony. (2009). "El estrcturalismo, el post-estructuralismo y la producción de la cultura", en Anthony Giddens y Jonathan Turner (coordinadores), La teoría social hoy, Alianza Universidad, Madrid.

Goffman, Erving. (1959). The Presentation of Self in Everyday Life, Dobleday, Nueva York.

-- (2005). Interation Ritual. Essaus in Face to Face Behavoir, New Brunswick, Nueva York.

Leonard, Annie. (2013). La historia social de las cosas, FCE, México.

Levi_Strauss, Claude. Tristes Trópicos, Paidós, España.

Lipovetsky, Gilles. (2011). La era del vacío, Anagrama, Barcelona.

Malinowski, Bronislaw. (1972). Los argonautas del Pacífico occidental, Península, España.

Nivón Bolán, Eduardo. (2003). "Las contradicciones de la ciudad difusa", Alteridades, julio - diciembre, año 13, núm. 26, UAM-I, México.

Ramírez Kuri, Patricia. (1998). "Coyoacán y los escenarios de la modernidad”, en Néstor García Canclini (coordinador), Cultura y comunicación en la ciudad de México, Grijalbo, UAMI, México.

Simmel, Georg. (1977). Filosofía del dinero, Centro de Estudios Constitucionales, Madrid.

-- (1988). "Metrópoli y vida mental", en Mario Bassols y otros (coordinadores), Antología de sociología urbana, UNAM, México.

Turner, Víctor. (1992). The Anthropology of Performance, Performance Art Journal, Nueva York.

\section{3}

